\title{
SUPERVISORY MENTORING BY ADVISERS: RELATIONSHIPS WITH DOCTORAL STUDENT POTENTIAL, PRODUCTIVITY, AND COMMITMENT
}

\author{
STEPHEN G. GREEN \\ Krannert Graduate School of Management \\ Purdue University \\ TALYA N. BAUER \\ School of Business \\ Portland State University
}

\begin{abstract}
A 2-year, three-panel (T1-T3) longitudinal study of 233 entering Ph.D. students examined the relationships between student potential for mentoring, (i.e., attitudes and objective abilities at entry (T1), mentoring functions used by the faculty adviser (T2, T3), and student research productivity and commitment (T3). Student potential was found to predict the amount of psychosocial mentoring, career mentoring, and research collaboration provided by the adviser. Psychosocial mentoring and collaboration were not related to student productivity or commitment after controlling for the students' entering abilities and attitudes. Career mentoring at $T 2$ was negatively related to the students' affective commitment to their program at T3. Implications for our understanding of mentoring and future research are discussed.
\end{abstract}

A growing body of research argues that mentoring is related to positive outcomes for the protégé and the organization such as greater commitment, better socialization, better performance, higher salaries, and promotions (see for example, Chao, Walz, \& Gardner, 1992; Dreher \& Ash, 1990; Jacobi, 1991; Johnson \& Scandura, in press; Kram 1983, 1985; Scandura, 1992; Whitely, Dougherty, \& Dreher, 1991; Zuckerman, 1977). Consequently, there is interest in whether mentoring functions can be provided within formal relationships, for example, assigned mentors or supervisors, and whether benefits can be derived from those experiences (Burke \& McKeen, 1989; Chao et al., 1992; Fagan \& Ayers, 1985; Noe, 1988a; Scandura \& Schriesheim, 1994; Wilbur, 1987; Zey,

We would like to thank Marilyn J. Haring, Julie Huffer, Marlesa A. Roney, and Barbara T. Stahura for their contributions to this study and this manuscript. This research was partially supported by a grant from Sigma Xi and was presented at the Tenth Annual Conference of the Society for Industrial and Organizational Psychology, Orlando, FL.

Correspondence and requests for reprints should be addressed to Stephen G. Green, Krannert Graduate School of Management, Purdue University, West Lafayette IN 47907 or e-mail at Green@mgmt.purdue.edu. 
1988). The present study seeks to extend our understanding of the role of mentoring functions within supervisory relationships.

To date, only a few studies have focused on what has been termed "supervisory mentoring" (Scandura \& Schriesheim, 1994), or, the extent to which supervisors provide mentoring functions such as psychosocial support and career mentoring for subordinates (Douglas \& Schoorman, 1988; Scandura \& Schriesheim, 1994). In this work, the focus is on understanding the strength of mentoring functions a supervisor provides to a subordinate and how that affects subordinate behavior and outcomes. Douglas and Schoorman (1988) found that employees experiencing more of the career and psychosocial functions of mentoring with their supervisors, also experience higher levels of performance and commitment to the organization. Scandura and Schriesheim (1994) found that supervisory career mentoring was associated with higher salary and promotion rates for subordinates, after controlling for the quality of leader-member exchange. Supervisory career mentoring was not related to subordinate performance, however. Thus, the dynamics and consequences of supervisory mentoring appear similar to those found in other mentoring relations, but they have not been widely studied.

This research examines supervisory mentoring within the adviserstudent relationship during doctoral training. Within this context, we attempt to answer several questions about the use and influence of supervisory mentoring. First, we examine the relationship between student potential (i.e., ability, experience, and commitment), and the extent to which mentoring functions are provided by the faculty adviser. Second, the incoming student's potential and the mentoring functions he or she receives are examined in terms of their relative contributions to the student's later productivity and commitment to his or her program and career. This study is designed to assess whether mentoring functions add value after the student's own talents and work attitudes are taken into account. Third, this research corrects another limitation of previous work on mentoring. All previous research on formal or informal mentoring has been either retrospective, asking respondents to recount mentoring experiences, or cross-sectional. Thus, even where relationships between mentoring functions and other variables are found, one cannot establish the chronological order of events (Cook \& Campbell, 1979). The present study employs a 2-year, longitudinal design allowing potential to be assessed before supervisory mentoring can occur. In addition, the mentoring functions experienced at the end of their first year of training, as well as outcomes at the end of their second year are assessed. This design allows us to ensure that student potential preceded the mentoring functions received and that both student potential and supervisory 
mentoring preceded outcomes that might be related to the mentoring functions.

Before turning to the development of hypotheses, a few words are in order about the setting of this research and adviser mentoring. First, as supervisors of doctoral students, faculty advisers are expected and encouraged to provide mentoring functions, and such mentoring has been identified as a significant influence on the students' professional development (Jacobi, 1991; Merriam, 1983; Phillips, 1979; Rawles, 1980). Thus, the adviser-student relationship provides a rich opportunity to study how supervisory mentoring takes place and its consequences. Second, doctoral students just beginning their professional training in the "hard" sciences such as chemistry or physics, and engineering (Bigland, 1973), offered several advantages as a sample. This setting allowed us to examine a large sample of newcomers who were simultaneously entering similar settings, with similar expectations, where similar indicators of talent, (e.g., Graduate Record Examination [GRE] scores), and similar indicators of productivity (e.g., publications), are widely employed. This relative comparability of setting and experiences provided a good opportunity to study student potential and supervisory mentoring effects. Third, the effects of mentoring in this setting have important industrial implications. In 1987, Sigma Xi, the scientific research society founded in 1886 to honor scientists, recognize research, and promote scientific cooperation, called for renewed attention to the education of future scientists. They noted that the doctoral students of today will be the mainstay of our country's research and development in areas such as medicine, agriculture, and industry. Therefore, part of the motivation for studying supervisory mentoring of doctoral students in the "hard" sciences is to address Sigma Xi's concerns and to better understand the professional development of this important segment of our workforce. Finally, there is evidence that $R \& D$ and engineering functions within firms are attempting to develop supervisory mentoring as part of the supervisory process (Hissong, 1993; Kerkes, 1994; Marien, 1992; Parson, 1991). For example, Olin Corporation's TQM initiatives have asked supervisors to become coach-mentors who help subordinates improve their performance and their personal development (Marien, 1992). Thus, this research may be generalizable to industrial settings where these doctoral students are likely to be employed.

Given this research setting, our conception of mentoring functions was broadened to take into account the characteristics of the working relationships found there. The mentoring provided to students by their advisers was measured using Noe's (1988a) mentoring functions scale. In addition, a collaboration scale was developed to assess the extent to which the adviser invited the student to co-author research products. 
Previous research on graduate education and scientific productivity indicates that this is an important function of sponsorship or mentoring by faculty members that can be directly related to the career success of protégés (Busch, 1985; Cameron \& Blackburn, 1981). Therefore, in this work, supervisory mentoring is operationalized in terms of three functions: The amount of career and psychosocial functions (Noe, 1988a; Schockett \& Haring-Hidore, 1985) and research collaboration provided by the adviser.

\section{Student Potential and Mentoring}

A number of authors point out that there are potential benefits as well as costs to mentoring (Halatin \& Knotts, 1982; Hunt \& Michael, 1983; Kram, 1985; Ragins \& Scandura, 1993). Mentors appear to derive intrinsic satisfaction from "spotting new talent" (Phillips-Jones, 1982, p. 54) and watching the protégé grow and develop (Busch, 1985; Hunt \& Michael, 1983). Mentoring also is a source of social support for the mentor. The protégé comes to serve as a trusted and respected colleague (Busch, 1985; Jacobi, 1991). Mentoring also may enhance the mentor's performance and reputation or be the source of explicit rewards, especially in formal mentoring arrangements (Hunt \& Michael, 1983; Ragins \& Scandura, 1993). Similarly, mentoring can be costly, leading to frustration, exploitive or unhealthy relationships, or reduced performance on the part of the mentor (Halatin \& Knotts, 1982; Levinson, 1978; Ragins \& Scandura, 1993). Given these potential benefits and costs, individuals are likely to be selective in who they mentor and more inclined to provide mentoring to individuals who have more potential to deliver benefits, as opposed to costs, in that relationship. Although advisers, as supervisory mentors, are expected to mentor doctoral students, they do have discretion in how much effort they invest in that process. Students with greater potential are expected to be provided a greater degree of mentoring functions by their adviser.

Kram (1983) in her discussion of the initiation stage of mentoring echoes this logic by asserting that mentoring is more likely for protégés who are seen as having talent, drive, and positive attitudes toward their work. Additionally, Healy and Wechert $(1990$, p. 20$)$ point out that "... individuals must often show exceptional promise to be accorded protégé status." Noe (1988b) in his discussion of women and mentoring invoked the notion of leader-member exchange (Dansereau, Graen, \& Haga, 1975) as a good way to understand why mentoring relationships develop. He suggests that mentoring, an in-group relationship, develops when potential mentors perceive subordinates to be competent, trustworthy, and motivated to assume responsibilities (Noe, 1988b). 
Graen and Scandura's (1987) work on dyadic organizing also invokes the mentor-protégé dyad as an example of a highly developed dyadic work structure (p. 196). Only a small number of qualitative studies, however, support the contention that protégé potential is related to the formation of mentoring relationships (e.g., Kanter, 1977; Kram, 1983; Zuckerman, 1977). No specific empirical tests of the relationship between protégé potential and mentoring could be found. This study partially addresses that void by examining the influence of student potential on the use of mentoring functions within a supervisory mentoring relationship.

To summarize, it appears that protégé potential is likely to consist of both performance and nonperformance dimensions. Therefore, greater supervisory mentoring should be more likely when the student possesses characteristics that signal the adviser that the student is likely to be committed to his or her endeavors, has positive attitudes toward the adviser, and has the talent to succeed (i.e., to deliver benefits). Therefore, in this setting, student potential was assessed in those terms using a broadband approach in an attempt to capture the complexity of student potential. The incoming students' affective commitment to their program and their commitment to a research career were used as measures of student commitment. Whether the student chose his or her present university to work specifically with the professor serving as his or her adviser was used as an indicator of a positive predisposition toward the adviser. These variables were felt to indicate positive work attitudes that might be related to increased levels of supervisory mentoring by the adviser. In addition, indications of the student's ability to perform as a researcher and scholar were assessed in several ways. GRE scores on verbal and quantitative aptitudes were obtained from student records. The amount of research experience the student had before entering the program was measured. Finally, the student's first semester grade point average was obtained from student records, as another possible early indicator that this student is a strong performer, worthy of adviser mentoring.

Advisers can become aware of these indicators of potential through several mechanisms. Faculty members in a given area review applications before students enter, in some cases all the faculty members in an area will review student folders as part of the admission process. Moreover, discussions among faculty members about applicants or newly admitted students often focus on information about the student's prior experience, aptitude scores, or with whom they want to work. Similarly, after joining the program, advisers can work closely with the new student and thus are given opportunities to observe other indicators of the student's talent and commitment. In some programs, explicit reviews of doctoral student performance are held at the end of each semester where observations about students' talent and commitment are openly 
discussed among faculty members. Thus, it was expected that students who showed more promise to be productive researchers, and thus a benefit to the adviser's productivity and reputation, would receive more supervisory mentoring from the adviser (i.e., greater levels of the psychosocial function, career function, and collaboration). Based on the reasoning provided above, the following hypotheses were tested:

Hypothesis 1: The positive work attitudes of students at entry will be positively associated with the adviser providing more supervisory mentoring during the first year of the program;

Hypothesis 2: Indicators of student ability to perform at entry will be positively associated with the adviser providing more supervisory mentoring during the first year of the program.

\section{Potential, Mentoring Functions, and Outcomes}

Mentoring research gained much of its impetus from the belief that mentoring provided protégés with advantages that would translate into improved performance, satisfaction, and career outcomes. Kram (1985, p. 8) points out that mentoring can enhance the protégé's personal development, sense of competence, and self-worth. She also notes that mentors can help the protégé acquire critical skills and navigate more effectively in his or her organization. Thus, the protége is likely to become more optimistic and confident about his/her place and eventual success in the organization (Kram, 1985, p. 54-55). Such experiences and beliefs should lead to greater protégé satisfaction and commitment. Previous literature does demonstrate positive relationships between mentoring and other affective responses by the protégé such as satisfaction (Chao et al., 1992; Dreher \& Ash, 1990). Also, a single study did find a positive relationship between mentoring and commitment within a crosssectional design (Douglas \& Schoorman, 1988). Similarly, the careerrelated function provides the protégé with sponsorship, coaching, and exposure which are argued to directly contribute to his or her performance (Chao et al., 1992; Douglas \& Schoorman, 1988). In this setting, research collaboration also can directly aid the new doctoral student's productivity, success, and competence (Busch, 1985; Cameron \& Blackburn, 1981). Thus, there is reason to expect more mentoring to increase the protégé's commitment to the organization and to his or her career and enhance his or her productivity.

Nevertheless, research on mentoring outcomes has tended to focus on more distal protégé career outcomes such as salary and promotions (see, for example, Dreher \& Ash, 1990; Johnson \& Scandura, in press; Scandura, 1992; Scandura \& Schriesheim, 1994; Whitely et al., 
1991). Only a small set of management studies have examined mentoring effects on protégé performance and productivity (Chao et al., 1992; Douglas \& Schoorman, 1988; Scandura, 1992; Scandura \& Schriesheim, 1994). Research in educational settings has done a somewhat better job of examining outcomes by looking at mentoring and the research productivity of scientists (Jacobi, 1991). All of the management and educational research to date, however, used cross-sectional or retrospective designs. Therefore, it remains unclear whether mentoring actually preceded better performance by the protégé or was a response to it.

The role of protégé potential also raises an interesting issue in the study of mentoring outcomes. As Jacobi (1991) points out, the characteristics that indicate an individual has potential to be a protégé, such as the ability to perform, commitment, and organizational savyy, would probably make that person successful with or without a mentor. Therefore, one is left to question how much mentoring functions actually contribute to better performance and productivity by protégés. In reviewing both the management and education literature, several studies could be found that controlled for protégé characteristics when examining the influence of mentors on career success such as promotions or salary (Dreher \& Ash, 1990; Turban \& Dougherty, 1994; Whitely et al., 1991). Only one study was found, however, that attempted to control for any protégé characteristics (e.g., work experience, education, tenure, and amount of training), when examining mentoring effects on protégé performance (Scandura, 1992). Similarly, no work could be found that took into account the levels of protége commitment before mentoring or that simultaneously examined the relationships between commitment, productivity, and mentoring functions. If we are to understand the contributions that supervisory mentoring makes to protégés' careers, we need a more careful examination of how mentoring functions affect protegé performance on the job. Moreover, we need to disentangle mentoring function effects upon performance from those effects caused by the protégé's own talent and motivation. Our longitudinal design allows us to test this question.

Indicators of student abilities and commitment to their work were measured as newcomers entered their doctoral programs, before mentoring could take place. Similarly, measures of student productivity and commitment were collected after the onset of the mentoring functions. This allows the student's own influence on his or her outcomes to be partialled out before testing the effects of mentoring functions on those outcomes. Similarly, it assures that supervisory mentoring preceded outcomes and was not a response to them. These precautions provide for a more accurate test of the benefits of supervisory mentoring. In light 
of the previous theory and findings, more supervisory mentoring is expected to be associated with more productivity even after controlling for student ability and commitment. Therefore, it is hypothesized:

Hypothesis 3: After controlling for indicators of the student's ability to perform and initial levels of commitment, more supervisory mentoring by advisers will be positively related to greater productivity by the student.

This study also examines the relationship between mentoring functions and the students' affective commitment to the program and commitment to a research career. These commitment variables were included because, as noted earlier, high levels of commitment by students at entry were expected to attract more mentoring by advisers. In addition, retention of doctoral students is an active concern in higher education (Bowen \& Rudenstein, 1992) and commitment has been shown in educational contexts to be related to turnover (Pascarella \& Terenzini, 1980; Stoecker, Pascarella, \& Wolfle, 1988). Thus, to the extent supervisory mentoring increases student commitment, such mentoring could be an important factor in the retention of doctoral students in the hard sciences. As with the tests for mentoring effects on student productivity, the students incoming levels of commitment and ability will be partialled out before testing the mentoring function's relationships to the students' level of commitment at the end of 2 years in the program. By removing the influence of these incoming student characteristics on later commitment, the unadulterated relationship of mentoring functions to student commitment will be more evident. It is hypothesized:

Hypothesis 4: After controlling for indicators of the student's ability to perform and initial levels of commitment, more supervisory mentoring by advisers will be positively related to greater commitment by students to their program and research careers.

\section{Method}

\section{Subjects and Procedure}

Entering doctoral students in 24 academic departments at a large Midwestern university were sampled. Departments were chosen using three criteria: each had a doctoral program, engaged students in research activities as an integral part of their training, and were classified as a "hard" science (Bigland, 1973). These criteria ensured that research activity was a relevant task for this sample. They also limited the sample to a set of sciences where a relatively homogeneous set of 
training experiences would exist while still maintaining adequate sample size. Finally, the sample also reflects our desire for this work to be pertinent to Sigma Xi's concerns about the training of the future scientists and engineers. Assessment of departments on these criteria was based upon statements appearing in the university catalog describing the programs and upon personal verification of the departments' operations. This study is an extension of previous research on newcomer socialization (Bauer \& Green, 1994) that examined the influence of preentry experiences and professional activities on the accommodation and outcomes of incoming doctoral students at the end of their first year. Therefore, this sample and some measures (e.g., prior experience, affective and career commitment at Time 1 [T1] and early performance measures) overlap with that prior work. A third year of data collection was conducted, however, and all Time 3 (T3) data, archival data, mentoring data, and data collected from other organizational members are unique to this study. A detailed description of the data overlap between the two studies is available from the first author upon request.

A total of 357 incoming doctoral students were identified in the Fall of 1991. Questionnaires were sent to all students during the first 3 weeks of the academic school year (T1). Participants were told that the purpose of the study was to examine the experiences of doctoral students during their training. Questionnaires were not anonymous, but confidentiality was assured and human subjects approval was obtained from the university. Questionnaires were distributed and returned through the university mail system. After several follow-ups to obtain missing questionnaires, a total of 233 questionnaires were returned. This yielded a T1 response rate of $65 \%$. Data were collected a second time (T2) 3 weeks prior to the end of the students' first academic year. The response rate of eligible respondents at $T 2$ was $84 \%(n=195 / 233)$. Data were collected a third time (T3) 3 weeks prior to the end of the students' second academic year. The response rate of eligible respondents was $83 \%$ ( $n$ $=161 / 195)$. In this sample, $77 \%$ of the students were male, $62 \%$ were White, and $60 \%$ were U.S. citizens. A comparison of nonrespondents at $\mathrm{T} 2$ and $\mathrm{T} 3$ with respondents revealed two differences. Nonrespondents had significantly lower grade point averages the first semester $(t$ $=2.50, d f=203 ; p<.01)$ and reported significantly more career mentoring ( $t=2.17, d f=193, p<.03$ ) than respondents. It may be that nonrespondents were receiving counseling about their performance and career demands.

In addition, independent of the data collection for this study, we assessed the extent to which mentoring was an expected function for faculty advisers and how important such mentoring was seen to be for students 
during their first 2 years of their doctoral studies. We wanted to empirically establish that the mentoring functions are expected, valued, and significant events for doctoral students in the 24 departments chosen for study. For each department in the study, a questionnaire was sent to the department head ( $83 \%$ response rate), two faculty members within the department ( $93 \%$ response rate), and two upper-level doctoral students (71\% response rate) chosen by the department head (overall response rate $=80 \%$ ). As expected, respondents strongly agreed that faculty advisers were expected to "sponsor, protect, and provide challenging tasks, exposure, and visibility for the Ph.D. students they advise," such as provide the career function within mentoring ( $94 \%$ yes response). Similarly, faculty advisers were expected to "provide counseling, acceptance, confirmation, and coaching," or the psychosocial function (93\% yes response). When asked "Are faculty advisers expected to mentor Ph.D. students they advise?" 96\% responded yes. Thus, it is clear that supervisory mentoring is expected of faculty advisers.

The importance of the adviser-student relationship during the first 2 years of doctoral study was also assessed to determine if mentoring during this period plays a significant role in the student's development. Respondents indicated that the adviser-student relationship was "very important" for student development (87\%), student productivity (75\%), and student commitment $(62 \% ; 31 \%$ responded it was "somewhat important"). In addition, $86 \%$ of the respondents indicated that "doctoral training during the first 2 years in the program is equally or more important when compared to the last 2 years' training." Moreover, respondents estimated that $97 \%$ of the advisers during the first 2 years go on to be the student's doctoral dissertation chair. Thus, for the departments we studied, the adviser-student relationship during the first 2 years is seen as having a potentially significant influence on the student.

\section{Measures}

Where possible, established measures with known psychometric properties were used. Other measures were created based on literature reviews and pilot testing of items and scales. Both created and established measures were factor analyzed using principle factors analysis with varimax rotation. Factors were determined using a combination of decision rules: Theoretical rationale, eigen values greater than 1 , the scree plot, and high loadings with the absence of cross loadings (Ford, MacCallum, \& Tait, 1986). Specific cases of dropped items are reported where they occurred. One factor was obtained for each measure. In addition, all measures were tested for internal consistency and all Cronbach alphas exceeded the .70 level recommended by Nunnally (1978). 
Table 1 contains descriptive statistics and the correlation matrix for all measures. Specific measures are described below.

Four variables were used as indicators of the students' potential abilities to perform in their doctoral program. Both Verbal and Quantitative Aptitude scores (GRE) for the incoming students and first semester grade point average (grades) were obtained from student records. Scores and grades were provided by the Registrar's office after they had been transformed by adding a constant that was unknown to the researchers. This allowed the actual values of the students' scores to be disguised to maintain the confidentiality of that information while still maintaining the variance of those scores (Cohen \& Cohen, 1983 pp. 34-36). Finally, an index measuring the student's experience with research prior to entering the doctoral program was developed. Prior experience (collected at T1) measured the extent to which the student had experience with 10 research-related activities such as working on a research project with a faculty member, submitting a convention paper, or having a journal article accepted for publication $(1=$ never; $5=$ many times $)$. The responses were summed to create an measure of prior research experience where a higher score indicates more experience.

Commitment (collected at T1 and T3) was measured in two different ways. Affective commitment was measured adapting seven items from a previously developed measure (McGee \& Ford, 1987; Meyer \& Allen, 1984). Respondents indicated their agreement $(1=$ strongly disagree; 5 = strongly agree) with a statement such as, "I feel a strong sense of belonging to my graduate program." Research career commitment was measured using a scale developed for this study. This measure assessed the degree to which respondents valued pursuing a research career and activities now and in their future. Factor analysis led to dropping one item with a low loading from the scale. Therefore, the final measure was the average of six items such as "I am committed to a research career"; "Research is more important than teaching"; "After graduation, I want a job with a strong research orientation" ( $1=$ strongly disagree; $5=$ strongly agree). Affective and Career Commitment have a relatively low average intercorrelations across T1 and T3 (avg. $r=0.25$ ) and previous work has supported the discriminant validity of these two types of commitment (Bauer \& Green, 1994).

Targeted adviser (collected at T2) measured whether students joined their programs to work with the particular professor who was subsequently served as their adviser $(0=n o ; 1=y e s)$. It was reasoned that if a student joined a program to work with a particular professor and then worked with that faculty member as his or her adviser, the student might be seen by the adviser as being more committed to working with 





him or her. Sixty percent of the students indicated that they joined their program to work with a specific professor.

Mentoring (collected at T2 and T3) was measured in terms of the extent to which the adviser provided the career-related function, the psychosocial support function, and research collaboration for the student. The 21-item scale developed and validated by Noe (1988b) was used to measure the career and psychosocial functions. The wording of the items was adapted to this work context. In addition, one item that dealt with "future advancement" (item 19, Noe, 1988a p. 469) was judged not relevant to this academic context and was dropped from the scale. The psychosocial function subscale consisted of 14 items assessing the coaching, acceptance, confirmation, role modeling, and counseling provided by the adviser. The career-related function subscale was composed of 6 items assessing the protection, exposure and visibility, sponsorship, and challenging assignments provided by the adviser. Responses to the mentoring items ranged from $1=$ to a very slight extent to $5=$ to a very large extent. Factor analysis of the scales yielded two factors with the career function items loading on one factor for the most part (one cross loading). Seven of the psychosocial items, however, did cross load on both the psychosocial and the career factors. Theory and measure development, however, have argued that these two functions are different constructs (Noe, 1988a) and these scales have been so used in other research (e.g., Chao et al., 1992). In addition, in this research the effects of one function are always controlled for when testing for the effects of the other function. Therefore, it was decided to retain the scales in their original form. Scales were created from an average of items composing that scale. A collaboration scale (collected at T2 and T3) was adapted from Green (1991) and measured the extent to which the adviser invited the student to co-author five different types of research products: a research paper, a paper to be submitted to a journal, a paper to be submitted to a conference, a grant proposal, and a book or book chapter ( 1 $=$ never, $5=$ many times $)$. These items were summed to create a single collaboration scale.

Publications and submissions were used as two measures of research productivity adopted from prior work (Bauer \& Green, 1994). Respondents were asked to report at $\mathrm{T} 2$ and $\mathrm{T} 3$ the number of convention papers, journal articles, book chapters, and grants/contracts that had been accepted within the last year. Each acceptance was coded as one "publication." The definition of a publication is purposely broad to help increase the variance among participants and to allow for differences across departments in what is considered research productivity for a given field. For hypothesis testing, the number of publications was 
summed across the 2 -year period. Across the 2 years, $53 \%$ of the participants had one or more publications. Of those who had published, the average number of publications was $2.42(S D=2.05)$.

Respondents also were asked to report the number of submissions they had within the last year to each outlet noted above. The number of publications was subtracted from the number of submissions so that the submission variable would be independent from the publication score and represent submissions that were not yet published. For hypothesis testing, the number of submissions was summed across the 2-year period. Across the 2 years, $41 \%$ of the participants had one or more submissions. Of those who had submitted, the average number of submissions was $1.84(S D=1.23)$. Publications and the adjusted submissions variables were correlated at .37 .

\section{Control Variables}

Five variables were examined for their potential influences on student characteristics, mentoring, and outcomes: department, gender of the student, citizenship (U.S. vs. international) of the student, whether the students adviser was assigned (84\% assigned advisers), and whether the student had been an undergraduate at the university prior to entering the doctoral program $(n=20)$. Our concern here was that mentoring functions by the adviser might differ significantly for these different categories of students and thus confound our findings. Analysis of variance of student responses showed no significant differences on any of the variables in the study for gender or for assigned versus not-assigned advisers. Therefore, these control variables were dropped from further consideration. Some significant differences were found across departments, citizenship, and previous undergraduate work at the university. Given the large number of departments $(n=24)$, it was impractical to control for departmental differences by entering dummy codes within the regressions. Therefore, all variables within the study were standardized to a mean of 0 and a standard deviation of 1 within each department. Follow-up analysis of variance revealed that this procedure removed all differences across departments. Hypothesis testing was performed using these standardized variables. Citizen $(0=$ international; $1=$ U.S. $)$ and undergraduate status $(0=$ no undergraduate work at this university; 1 = previous undergraduate work at this university) were entered as dummy-coded control variables in all analyses where they were found to be correlated to the criteria being examined. 


\section{Results}

Before hypothesis testing, the sample was examined to see if students had maintained the same adviser since entering the program. A total of 21 students reported changing their adviser at some time during the 2 years of data collection. A comparison of these students to students who did not change advisers revealed two differences. Students who changed advisers were less likely to have a targeted adviser (24\%) than students who did not change advisers (60\% with a targeted adviser; $\chi^{2}=9.74, p<$ $.05)$. Similarly, students who changed advisers reported having less career mentoring at $\mathrm{T} 2$ (mean $=-.54$ ) than students who did not change (mean $=.07, t=2.81, p<.05$ ). To ensure that student reports about supervisory mentoring were consistently referring to the same adviser, however, these 21 students were dropped from the sample before hypothesis testing. In addition, the students' grades in their first semester in the program showed no significant relationships with any of the variables under study (see Table 1). Therefore, to preserve degrees of freedom and power, this variable was dropped from further consideration. Finally, to maintain sample size for multivariate hypothesis testing within the longitudinal design, the recommendations of Tabachnick and Fidell (1983) for replacing missing data were followed and mean replacement for individual items was conducted for all measures.

For hypothesis testing, a structural equations approach was considered, but not used primarily due to the changing sample size over time. For example, LISREL, using listwise deletion, would limit the test of all paths to the smallest sample size across the three panels of data. This would require dropping 34 cases where usable data were available for analyses testing relationships between $\mathrm{T} 1$ and $\mathrm{T} 2$. Therefore, Cohen and Cohen's (1983, pp. 361-366) analytical strategy for estimating partial causal models with the hierarchical analysis of sets of variables was utilized. Within the analysis, the student work attitudes and ability measures, the mentoring functions, as well as the student commitment and productivity outcomes were each treated as a set of variables with no causal relationships specified between variables within these sets. OLS regression was used to estimate the effects of the hypothesized variables on the mentoring functions and outcome variables in the model.

The first two hypotheses proposed that the positive work attitudes of the students (Hypothesis 1) and indicators of ability to perform at entry (Hypothesis 2) would be positively associated with more supervisory mentoring later in the program. As can be seen in Table 1, the mentoring functions were related to the students' work attitudes and to indicators 
TABLE 2

Regression of Time 2 Supervisory Mentoring Functions on Entry Variables

\begin{tabular}{lccc}
\hline \hline Predictors & Psychosocial & Career & Collaboration \\
\hline Verbal GRE & $.19^{*}$ & $.20^{*}$ & .01 \\
Quantitative GRE & $-.18^{*}$ & -.12 & $.15^{+}$ \\
Prior experience & .02 & $.14^{+}$ & $.17^{*}$ \\
Targeted adviser & .06 & $.12^{+}$ & $.17^{*}$ \\
Affective commitment & $.37^{*}$ & $.15^{*}$ & .06 \\
Career commitment & .09 & $.24^{*}$ & -.02 \\
Citizenship & na & na & -.13 \\
Undergraduate school & na & na & $.16^{*}$ \\
$\quad F$ value & $5.36^{*}$ & $5.76^{*}$ & $3.48^{*}$ \\
$R^{2}$ & .17 & .18 & .16 \\
$d f$ & $(6,160)$ & $(6,160)$ & $(8,150)$ \\
\hline
\end{tabular}

Note: Cell entries are standardized coefficients. Unstandardized coefficients are not shown because they are essentially equivalent due to standardizing of the data by department. All statistical significance values are based on two-tailed tests.

${ }^{*} p<.05 ; \quad+p<.10$

of the ability to perform. Having a targeted adviser, affective commitment, and career commitment at the outset were all positively related to several mentoring functions. Similarly, quantitative aptitude scores and prior experience showed positive zero-order relationships with several mentoring functions. As can be seen in Table 2, support also was found for both of these hypotheses in the regression analyses that controlled for relationships among predictors. Students with more commitment to a research career at $\mathrm{T} 1$, higher affective commitment at $\mathrm{T} 1$, more prior experience, a targeted adviser, and higher verbal scores report their advisers using more career mentoring behavior at $T 2$. Similarly, students who entered the program with higher verbal GRE scores, lower quantitative GRE scores, and stronger affective commitment at T1 did report their advisers using more psychosocial mentoring behavior during their first year of study (T2). The negative relationship between quantitative GRE scores and psychosocial mentoring, however, is a contra-hypothesis finding. Finally, students who entered the program with higher quantitative GRE scores, more prior research experience, and came specifically to work with their adviser reported more research collaboration between themselves and their advisers.

Hypothesis 3 proposed that the mentoring functions would be positively related to greater productivity by the student, after controlling for indicators of the student's ability to perform and early commitment. Collaboration did have a zero-order relationship to student research submissions $(p<.07)$. Similarly, the use of the career mentoring function and collaboration did have significant zero-order relationships to publications by students (see Table 1). As can be seen in Table 3, however, the 
TABLE 3

Regression of Time 3 Outcomes on Time 2 Supervisory Mentoring Controlling for Variables

\begin{tabular}{lcccc}
\hline \hline Predictors & Publications & Submissions & Affective com. & Career com. \\
\hline Verbal GRE & .10 & .11 & -.07 & .01 \\
Quantitative GRE & -.05 & -.04 & .02 & .02 \\
Prior experience & $.25^{*}$ & $.19^{*}$ & .09 & -.01 \\
Targeted adviser & $.16^{+}$ & .10 & .02 & .01 \\
Affective commitment & -.04 & -.04 & $.52^{*}$ & .04 \\
Career commitment & .01 & $-.21^{*}$ & .02 & $.73^{*}$ \\
Psychosocial & .00 & .10 & .15 & .00 \\
Career & .07 & -.05 & $-.19^{*}$ & -.06 \\
Collaboration & .14 & .14 & -.09 & -.05 \\
Citizenship & na & na & na & .08 \\
Undergraduate school & .10 & .06 & na & na \\
$\quad F$ value & $2.92^{*}$ & $1.89^{*}$ & $7.51^{*}$ & $12.95^{*}$ \\
$R^{2}$ & .19 & .14 & .35 & .51 \\
$\quad d f$ & $(10,121)$ & $(10,121)$ & $(9,128)$ & $(10,127)$ \\
\hline
\end{tabular}

Note: Cell entries are standardized coefficients. Unstandardized coefficients are not shown because they are essentially equivalent due to standardizing of the data by department. All statistical significance values are based on two-tailed tests.

${ }^{*} p<.05 ; \quad{ }^{+} p<.10$

use of the career mentoring function by advisers and collaboration show no significant relationships to T3 productivity after controlling for student potential and other mentoring functions. Thus, we have no support for Hypothesis 3 that proposed that greater use of mentoring functions by advisers will positively contribute to student productivity, beyond student potential.

Student characteristics, on the other hand, do have relationships to productivity and commitment. The number of research submissions were positively related to prior experience (see Table 1). After controlling for other influences in the regression analysis, greater prior experience still was related to more submissions by the student (see Table 3). Lower career commitment at entry also emerged as a significant predictor of submissions in the regression findings. In addition, the number of student publications had a positive relationship with prior experience and having a targeted adviser both in the zero-order correlations and in the regression findings (see Tables 1 and 3 , respectively).

Finally, the effects of the mentoring functions upon the commitment of the students at the end of their second year of doctoral studies was tested. Hypothesis 4 predicted that the mentoring functions would be positively related to student commitment, after controlling for student characteristics at entry. As can be seen in Table 1, for both affective and career commitment, the initial levels of commitment at the time of entry to the program were the best predictors of commitment 2 years 
later. This finding still held true in the regression analyses (see Table 3 ). Moreover, commitment to a research career had no relationship to the advisers use of any of the mentoring functions. Affective commitment did have a significant positive zero-order relationship to the advisers use of psychosocial mentoring behaviors. As can be seen in Table 3, however, the psychosocial mentoring function no longer has a significant relationship to affective commitment when the student's potential and other types of mentoring functions are taken into account. Also, in the regressions, students who reported more career mentoring at $\mathrm{T} 2$ (the end of their first year in their program) reported somewhat lower affective commitment at $\mathrm{T} 3$ (the end of their second year) after controlling for the other potential predictors.

\section{Discussion}

This examination of supervisory mentoring of doctoral students in the sciences reveals some results that differ from the findings of mentoring studies in other contexts. The psychosocial and career-related functions that Noe (1988a) identified in his original development of the mentoring measure were more strongly correlated in this study ( $0.48 \mathrm{vs.}$ 0.65 respectively). This may say something about how adviser mentoring occurs in graduate education. The adviser and doctoral student are joined in a training effort where the adviser is responsible for the professional development of the student. Under those circumstances, within a formal teacher-student relationship, mentoring appears to blend psychosocial and career-related functions. This blending of mentoring functions may be unique to training or educational contexts, but other authors have also reported unidimensional representations of the mentoring construct (Dreher \& Ash, 1990). This suggests that the functions of mentoring may be contextually bound appearing multidimensional in some contexts and unidimensional in others (e.g., Schockett \& HaringHidore, 1985). More work on measurement development is needed and should investigate this possibility.

It was also the case in this study that some of the biases associated with mentoring in the past did not appear to be a factor here. Even though $90 \%$ of the advisers were male, there was no evidence that female students $(23 \%)$ experienced any differences in the extent to which the advisers provided supervisory mentoring. This finding replicates Dreher and Ash's (1990) findings for informal mentoring in industrial settings. Similarly, $89 \%$ of the advisers were U.S. citizens, but we found only one difference between the supervisory mentoring experienced by international and U.S. students. International students were more likely to collaborate on research with their adviser by the end of their first year in 
the program than were domestic students. Thus, in this context, supervisory mentoring appears to have avoided some of the concerns about bias raised in other contexts (e.g., Hunt \& Michaels, 1983; Kram, 1985; Ragins \& Cotton, 1991), a reassuring finding for educators.

The relationship found between Noe's (1988a) mentoring functions and collaboration was informative and serves to validate the differences between the psychosocial and career functions. Given the common interpretation of mentoring as a process where more senior individuals use their experience and influence to help the advancement of a protégé (see, for example, Kram, 1985; Noe, 1988a; Olian, Carroll, Giannantonio, \& Feren, 1988; Philips-Jones, 1982), we expected research collaboration to be a natural extension of that process in the training of doctoral students. Examining the correlations between Noe's (1988a) original mentoring measures and collaboration revealed that collaboration had very low correlations with the advisers use of the psychosocial functions at $\mathrm{T} 2(r=.08)$, but stronger correlations with the advisers use of the career-related function at $\mathrm{T} 2(r=.19, p<.02)$. The convergence of collaboration with the career mentoring function is expected given the importance of research productivity in academic careers. Nevertheless, the low amount of shared variance between collaboration and the other mentoring functions, raises a question about the role of collaboration. Students may be making contributions to the adviser's own productivity with the adviser paying little attention to the value of collaboration as a mentoring function. Similarly, collaboration may be seen by students as an instrumental activity focusing primarily on their own productivity, not on their relationship with their adviser.

It was hypothesized that advisers looked for potential in incoming students and would provide more mentoring functions with students who appeared to have the ability to perform well and had positive attitudes toward their work upon entering the program. This hypothesis was well supported providing the clearest empirical evidence to date that the mentoring functions are more likely to be available to the most capable newcomers. Incoming students who had higher verbal aptitude and stronger commitment to the program reported their advisers providing significantly higher levels of psychosocial and career mentoring functions at the end of their first year in their program. Similarly, entering students with more prior experience and a targeted adviser experienced more career mentoring. Thus, mentoring functions appear to be used to develop the best talent and may be an outcome of a merit system. Although this study focused on supervisory mentoring, similar protégé potential effects are possible and expected to occur in informal mentoring relationships. 
Unexpectedly, students with higher quantitative aptitude reported lower levels of psychosocial mentoring, a contra-hypothesis finding. This relationship emerged only after controlling for other variables, however, so one should interpret it with caution. Quantitative aptitude, along with prior experience and a targeted adviser, was also related to more collaboration with the adviser. For collaboration to occur, the emphasis seems to be on technical skills and a pre-existing motivation on the part of the protégé to work with the adviser. Commitment and verbal aptitude were inconsequential. From this set of findings a pattern emerges that indicates that students with significant research skills at the outset formed a different relationship with their advisers. The students' higher quantitative aptitude and prior research experience had direct applicability to the research tasks and were related to student productivity. These students, coming into the supervisory mentoring situation, then appeared to put their energy into collaborative efforts, even to the exclusion of psychosocial interactions. This task focus, however, did not affect the students' commitment in any way. This suggests that supervisory mentoring may not require that all functions be provided to all subordinates. In some contexts, mentoring may take on compensatory characteristics where emphasis on one function may compensate for the lack of other functions. Future research might explore this possibility.

The findings for supervisory mentoring and student outcomes were less encouraging. The use of the psychosocial, career, and collaboration functions were not found to be related to student productivity, after controlling for other potential influences in the model. Similarly, these mentoring functions were not related to student commitment in the model except for the negative relationship of career mentoring to affective commitment. There were a number of zero-order relationships between mentoring variables and these outcomes, however. Thus, controlling for the other influences on these outcomes, including student potential, did reduce the relationships of the mentoring functions to outcomes typically attributed to these mentoring functions. This suggests that when studying mentoring effects, one should take into account protégé attributes that exist prior to mentoring. They were found here to confound the relationships between mentoring functions and later outcomes.

Entering characteristics of students were related to student productivity, however. Students with more prior experience produced more publications and more paper submissions. Similarly, having a targeted adviser was related to more publications. The negative relationship between incoming career commitment and the number of submission is certainly counterintuitive. These data cannot explain this finding and 
one can only speculate on its meaning. Perhaps highly committed students become involved in larger projects or attempt to do more work on their own, thus slowing down their number of submissions. If this pattern is replicated in other work, it deserves more attention. Finally, it should be noted that very little was related to the research career commitment of the students. Given the evidence that mentors may help career advancement in other contexts, we expected the support and collaboration of the advisers to strengthen the students' commitment to their careers in research. Instead, students entered with high levels of commitment to research careers and that commitment was stable over the 2 years. The correlation between career commitment at $\mathrm{T} 1$ and $\mathrm{T} 3$ was 0.69 . This may be a characteristic peculiar to doctoral training. Students make a significant career decision to enter such programs.

This research suffers from limitations that should be acknowledged. In some cases, it would have been desirable to verify self-reports about prior experience and productivity. Unfortunately, this was not possible in this context. On the other hand, these measures often asked respondents to report specific events (e.g., have you ever submitted a paper to a conference), which have been argued to be more reliable than other types of self-reports (Ericsson \& Simon, 1980; Smith \& Miller, 1978; White, 1980). In addition, a number of archival measures (e.g., GRE scores) were employed. Similarly, we cannot disallow the possibility of biases where within-person correlations were used. Nevertheless, participant responses were separated in time, by as much as a year or more, thus reducing tendencies for consistency in responding (Podsakoff \& Organ, 1986). These precautions increase our confidence in the findings.

Similarly, one must acknowledge that this study only examined a set of possible influences on these mentoring processes. Omitted variables that might affect supervisory mentoring and student outcomes must be considered. Certainly, students may have had mentors other than their advisers helping them in their programs and these relationships could be related to student outcomes. Those relationships, however, were not the focus of this research. Future research should seek other variables that may serve as antecedents, mediators, and outcomes in this type of supervisory mentoring.

These findings and their interpretation also must take into account the uniqueness of this sample. Advisers do operate as supervisory mentors, but that role is a significant part of their job as faculty members and teachers. Nevertheless, there is evidence that supervisory mentoring is becoming a more common part of the supervisory role in industrial settings where doctoral students in the sciences and engineering are likely to be employed. In both R\&D and engineering, supervisors are being called upon to incorporate mentoring into their management roles 
(Hissong, 1993; Kerkes, 1994; Marien,1992; Parson, 1991). These findings would seem relevant to managers and subordinates in such settings. Moreover, the recent work demonstrating the effects of mentoring functions within nonscientific supervisor-subordinate relationships suggests that the findings of the present research may generalize to other managerial settings (Douglas \& Schoorman, 1988; Scandura \& Schriesheim, 1994). We would argue that the questions and observations made here are worthy of further consideration in studying mentoring in other settings.

This research makes several contributions and raises some important questions for future examination. By specifically examining the students' ability and commitment before mentoring occurred, we can now see that the potential of prospective protégés may affect a number of functions associated with mentoring. Future research on formal and informal mentoring needs to more explicitly take into account the talents and attitudes of protégés when trying to understand the role of mentoring in developing individuals within organizations. Also, the explicit examination of the mentoring functions' relationship to student productivity yielded some troubling findings. Mentoring functions, as commonly measured in terms of psychosocial or career-related functions, showed no relationship to the performance of students after the students' abilities and commitment were controlled for. If this finding were to generalize to other settings, and Scandura (1992) did have similar findings in a manufacturing setting, one must wonder what the mechanisms are by which mentors appear to affect protégé career outcomes such as salary and promotions. We assumed that mentoring made protégés better performers, therefore helping them to advance. The findings here call that logic into question, unless we enlarge mentoring to include processes such as collaboration.

Are mentors advancing protégés' careers through sponsorship, exposure, or visibility (Kram, 1985) even when protégés are performing no better than others on some important dimensions of performance such as research productivity? Perhaps mentors contribute to broader dimensions of performance such as political and social skills. Is that what organizations want from mentoring? Finally, the strongest findings were that mentoring is more likely for talented newcomers. Thus, corporations that rely on supervisors to provide mentoring need to be careful. These findings suggest that supervisors will provide more psychosocial and career mentoring functions to employees with higher ability. Is this what the organization wants? Also, what does this research say about assigned mentor programs where mentoring is sometimes hoped to be a way to help newcomers or employees at risk? Findings for assigned mentors have been mixed (see, for example, Chao et al., 1992; Noe, 
1988a). Perhaps mentoring is more driven by protégé potential than we expect, making it difficult for assigned mentors to support less talented protégés. Similarly, what does this say about the value of informal mentoring? If informal mentors tend to choose talented protégés, are they adding value? Future studies of formal and informal mentoring should examine the role of protégé potential in such relationships.

\section{REFERENCES}

Bauer TN, Green SG. (1994). The effect of newcomer involvement in work-related activities: A longitudinal study of socialization. Joumal of Applied Psychology, 79, 211-223.

Bigland A. (1973). The characteristics of subject matter in different academic areas. Joumal of Applied Psychology, 57, 195-203.

Bowen WG, Rudenstein NL. (1992). In pursuit of the Ph.D. Princeton, NJ: Princeton University Press.

Burke RJ, McKeen CA. (1989, Winter). Developing formal mentoring programs in organizations. Business Quarterly, 53, 76-79.

Busch JW. (1985). Mentoring in graduate schools of education: Mentors' perceptions. American Educational Research Journal, 22, 257-265.

Cameron SW, Blackburn RT. (1981). Sponsorship and academic career success. Journal of Higher Education, 52, 369-377.

Chao GT, Walz PM, Gardner PG. (1992). Formal and informal mentorships: A comparison on mentoring functions and contrast with nonmentored counterparts. PERSONNEL PSYCHOLOGY, 45, 619-636.

Cohen J, Cohen P. (1983). Applied multiple regression/correlation analysis for the behavioral sciences. New York: Erlbaum.

Cook TD, Campbell DT. (1979). Quasi experimentation: Design and analysis for field settings. Boston: Houghton Mifflin.

Dansereau F Jr, Graen GB, Haga WJ. (1975) A vertical dyad linkage approach to leadership within formal organizations: A longitudinal investigation of the role-making process. Organizational Behavior and Human Performance, 13, 46-78.

Douglas CA, Schoorman FD. (1988, August). The impact of career and psychosocial mentoring by supenisors and peers. Paper presented at the 1988 Academy of Management Meetings, Anaheim, CA.

Dreher GF, Ash RA. (1990). A comparative study of mentoring among men and women in managerial, professional, and technical positions. Joumal of Applied Psychology, $75,539-546$.

Ericsson KA, Simon HA. (1980) Verbal reports as data. Psychological Review, 87, 215-251.

Fagan MM, Ayers K Jr. (1985). Police mentors. FBI Enforcement Bulletin, January, 8-13.

Ford JK, MacCallum RC, Tait M. (1986). The application of exploratory factor analysis in applied psychology: A critical review and analysis. PERSONNEL PSYCHOLOGY, 39, 291-314.

Graen GB, Scandura TA. (1987). Toward a psychology of dyadic organizing. Research in Organizational Behavior, 9, 175-208.

Green SG. (1991). Professional entry and the adviser relationship. Group \& Onganization Studies, 16, 387-407.

Halatin TJ, Knotts RE. (1982). Becoming a mentor: Are the risks worth the rewards? Supenisory Management, 27, 27-29. 
Healy CC, Wechert AJ. (1990, December). Mentoring relations: A definition to advance research and practice. Educational Research, 32, 17-21.

Hissong D. (1993). Excel in your engineering. Chemical Engineering, 100, 157-160.

Hunt DM, Michael C. (1983). Mentorship: A career training and development tool. Academy of Management Review, 8, 475-485.

Jacobi M. (1991). Mentoring and undergraduate academic success: A literature review. Review of Educational Research, 61, 505-532.

Johnson NB, Scandura TA. (in press). The effects of mentorship and sex-role style on male/female earnings. Industrial Relations.

Kanter RM. (1977). Men and women of the corporation. New York: Basic Books.

Kerkes DJ. (1994). Precepts of project management. Civil Engineering, 64, 70-72.

Kram KE. (1983). Phases of the mentor relationship. Academy of Management Joumah 26, 608-625.

Kram KE. (1985). Mentoring at work: Developmental relationships in organizational life. Glenview, IL: Scott Foresman.

Levinson D. (1978). The seasons of a man's life. New York: Knopf.

Marien BA. (1992). Quality in R\&D: Putting TQM into the performance review process. Research Technology Management, 35, 39-43.

McGee GW, Ford RC. (1987). Two (or more?) dimensions of organizational commitment: Reexamination of the affective and continuous commitment scales. Joumal of Applied Psychology, 72, 638-641.

Merriam S. (1983). Mentors and protégés: A critical review of the literature. Adult Education Quarterly, 33, 161-173.

Meyer JP, Allen NJ. (1984). Testing the "side-bet theory" of organizational commitment: Some methodological considerations. Journal of Applied Psychology, 69, 372-378.

Noe RA. (1988a). An investigation of the determinants of successful assigned mentoring relationships. PERSONNEL PSYCHOLOGY, 41, 457-479.

Noe RA. (1988b). Women and mentoring: A review and research agenda. Academy of Management Review, 13, 65-78.

Nunnally J. (1978). Psychometric theory (2nd ed.). New York: McGraw-Hill.

Olian JD, Carroll SJ, Giannantonio CM, Feren DB. (1988). What do protégés look for in a mentor? Results of three experimental studies. Joumal of Vocational Behavior, $33,15-37$.

Pascarella ET, Terenzini PT. (1980). Predicting freshmen persistence and voluntary freshmen attrition. Joumal of Higher Education, 51, 60-75.

Parson RJ. (1991). Enlightened management must lay a strong foundation in training new engineers. Industrial Engineering, 23, 34-38.

Phillips GM. (1979). The peculiar intimacy of graduate study: A conservative view. Communication Education, 28, 339-345.

Phillips-Jones L. (1982). Mentors and protegés. New York: Arbor House.

Podsakoff P, Organ D. (1986). Self-reports in organizational research: Problems and prospects. Joumal of Management, 12, 531-544.

Ragins BR, Cotton JL. (1991). Easier said then done: Gender differences in perceived barriers to gaining a mentor. Academy of Management Joumal, 34, 939-951.

Ragins BR, Scandura TA. (1993, April). Expected costs and benefits of being a mentor. Eighth Annual Conference of the Society of Industrial and Organizational Psychology, San Francisco, CA.

Rawles BA. (1980). The influence of a mentor on the level of self-actualization of American scientists. Unpublished doctoral dissertation, Western Michigan University, Kalamazoo.

Scandura TA. (1992). Mentorship and career mobility: An empirical investigation. Joumal of Organizational Behavior, 13, 169-174. 
Scandura TA, Schriesheim CA. (1994). Leader-member exchange and supervisor career mentoring as complementary constructs in leadership research. Academy of Management Journal, 37, 1588-1602.

Schockett MR, Haring-Hidore M. (1985). Factor analytic support for psychosocial and vocational mentoring functions. Psychological Reports, 47, 627-630.

Sigma Xi. (1987). A new agenda for science. New Haven, CT: Sigma Xi, The Scientific Research Society.

Smith ER, Miller FD. (1978). Limits on perspectives on cognitive processes: A reply to Nisbett and Wilson. Psychological Review, 85, 355-362.

Stoecker J, Pascarella ET, Wolfle LM. (1988). Persistence in higher education: A 9-year test of a theoretical model. Joumal of College Student Development, 29, 196-209.

Tabachnick B, Fidell L. (1983). Conditioning matrices: Cleaning up your act before analyzing data. In Tabachnick B, Fidell L (Eds.), Using multivariate statistics (pp. 66-85). New York: Harper \& Row.

Turban DB, Dougherty TW. (1994). Role of protégé personality in receipt of mentoring and career success. Academy of Management Journah, 37, 688-702.

White P. (1980). Limitation on verbal reports of internal events: A refutation of Nisbett and Wilson and of Ben. Psychological Review, 87, 105-112.

Whitely W, Dougherty TW, Dreher GF. (1991). Relationship of career mentoring and socioeconomic origin to managers' and professionals' early career progress. Academy of Management Joumal, 34, 331-351.

Wilbur JL. (1987). Does mentoring breed success? Training and Development Joumah, 41, $38-41$.

Zey MG. (1988). A mentor for all reasons. Personnel Joumal, 67, 46-51.

Zuckerman H. (1977). Scientific elite: Nobel laureates in the United States. New York: Free Press. 


\section{ERRATA}

In the article "The Influence of Upward Feedback on Self- and Follower Ratings of Leadership," by Leanne Atwater, Paul Roush, and Allison Fischthal, published in the March, 1995 issue, the following table was inadvertently omitted. We regret this error.

\section{TABLE 4}

Average Self- and Follower Ratings for Leaders in Each Agreement Category Before and After Feedback

\begin{tabular}{lccccc}
\hline \hline & \multicolumn{2}{c}{ Before feedback } & & \multicolumn{2}{c}{ After feedback $^{a}$} \\
\cline { 3 - 6 } Agreement category & Follower $^{a}$ & Self $^{a}$ & & Follower $^{b}$ & Self $^{a}$ \\
\hline Under-estimator & 4.15 & 3.50 & 4.10 & 4.02 \\
In agreement & 3.90 & 4.16 & 4.05 & 4.24 \\
Over-estimator & 3.14 & 4.38 & 3.72 & 4.17 \\
\hline$a$
\end{tabular}

${ }^{a}$ The three mean ratings across agreement categories differ significantly based on ANOVA results, $p<.01$. Pairs of means differ significantly for each of the four sets of three means (e.g., 4.15 vs. $3.90 ; 3.90$ vs. $3.14 ; 4.15$ vs. 3.14 ). Tukey's HSD tests, $p<.05$ were used.

${ }^{b}$ The three mean ratings across agreement categories differ significantly based on ANOVA results, $p<.01$. Two of the three pairs of means are significantly different using Tukey's HSD test, $p<.05 ; 4.10$ (under-estimators) and 4.05 (in agreement) do not differ significantly.

In the article "Evaluating Developmental Assessment Centers as Interventions," by Robert G. Jones and Mark D. Whitmore in the June, 1995 , issue, the following references were not printed. We regret this error.

\section{REFERENCES}

Klinger E. (1975). Consequences of commitment to and disengagement from incentives. Psychological Review, 82, 1-25.

Little BR. (1989). Personal project analysis: Trivial pursuits, magnificent obsessions and the search for coherence. In Buss DM, Cantor N (Eds.), Personality psychology: Recent trends and emerging directions (pp. 15-31). New York: Springer-Verlag.

Nathan BR, Alexander RA. (1988). A comparison of criteria for test validation: A metaanalytic investigation. PERSONNEL PSYCHOLOGY, 41, 517-535.

Silverman WH, Dalessio A, Woods SB, Johnson RL. (1986). Influence of assessment center methods on assessors' ratings. PERSONNEL PSYCHOLOGY, 39, 565-578.

Stone DL, Stone EF. (1985). The effects of feedback consistency and feedback favorability on self-perceived task competence and perceived feedback accuracy. Organizational Behavior and Human Decisions Processes, 36, 167-185. 